\title{
Smoke and particulate filters in endoscopic surgery reviewed during COVID-19 pandemic
}

\author{
Gratiana Oana Alqadi ${ }^{1,2} \cdot$ Amulya K. Saxena $^{1}$
}

Received: 18 April 2020 / Revised: 4 May 2020 / Accepted: 7 May 2020 / Published online: 28 May 2020

(c) Springer Nature Singapore Pte Ltd 2020

\begin{abstract}
Aim This study aimed to evaluate the efficacy of smoke filters for use in endoscopic surgery and their significance during the present COVID-19 pandemic caused by severe acute respiratory syndrome coronavirus 2 (SARS-CoV-2).

Methods The literature was reviewed by analyzing articles on PubMed using the search terms "smoke", "filter", and "laparoscopy".

Results A systematic literature search revealed six smoke filter clinical studies pertinent to endoscopic surgery. The studies focused on the different aspects and efficacy of these filters: (1) UGF1 filter (Pall Biomedical, St. Germaine en Laye, France) investigated captured mesothelial cells and other debris, (2) Valve-less trocar AirSeal ${ }^{\mathrm{TM}}$ (SurgiQuest, Orange, CT) fitted with an ultra-low particulate air (ULPA) filter investigated smoke evacuation and filtration to reduce exposure of staff to hazardous fumes, (3) automatic smoke evacuator (IES2, ERBE) equipped with ULPA identified 37 filtered carcinogenic substances, (4/5) the Tropian trocar (Tropian Tech., Gunpo, Korea), a charcoal filter, investigated in two studies focused on filtration of further hazardous compounds, and (6) charcoal/ULPA combination filter by Dyeing and Finishing Technology Institute investigated filtration rates of volatile organic compounds.

Conclusions Surgical plume can be cleared of hazardous chemical through smoke filters. There were six different filter studies identified with regards to endoscopic surgery which can aid in protecting the surgical staff from dangerous smoke by filtering cells, recirculating, and filtering gas, and removal of carbon-based substances. No clinical study has specifically investigated the removal of viruses by smoke filters including the SARS-CoV-2.
\end{abstract}

Keywords Smoke $\cdot$ Filter $\cdot$ Laparoscopy $\cdot$ Efficacy $\cdot$ Pneumoperitoneum

\section{Introduction}

The new severe acute respiratory syndrome coronavirus 2 (SARS-CoV-2) outbreak started in late 2019 and its spread has changed surgical practice around the world. Since this virus is largely transmitted via respiratory droplets, there has been great concern that medical procedures that generate aerosols pose a risk to medical staff. During laparoscopy, the pneumoperitoneum is created in the abdominal cavity

Amulya K. Saxena

amulya.saxena@nhs.net

1 Department of Pediatric Surgery, Chelsea Children's Hospital, Chelsea and Westminster Hospital NHS Fdn Trust, Imperial College London, 369 Fulham Road, London SW10 9NH, UK

2 Department of Paediatric Surgery, University of Medicine and Pharmacy “Carol Davila”, Bucharest, Romania under pressure where the insufflated $\mathrm{CO}_{2}$ is moist and concentrated. Whenever electrocautery or other energy-powered devices are used, smoke that arises along with by-products of electric decomposition of tissue is released into the operating room through ports by the positive intraabdominal pressure. Various reports have already studied the potential danger of laparoscopic smoke [1, 2]. Previous research has also demonstrated that laparoscopy can lead to aerosolization of viruses [2-4]. Thus, to minimize the risk of possible transmission of Coronavirus disease 2019 (COVID-19), the number of laparoscopic surgeries was reduced to a minimum since the start of the pandemic. There has been recent mention on the use of filters, if laparoscopy has to be performed, during the present SARS-CoV-2 pandemic [5]. The aim of this study was to determine the efficacy and data available on filters in laparoscopic surgery and assess the possible significance during the COVID-19 pandemic. 


\section{Methods}

The literature was systematically reviewed by analyzing articles on PubMed using the search terms "smoke", "filter", and "laparoscopy". Articles in English, which analyze the use of filters during laparoscopic procedures, were selected. The article was drafted according to the Preferred Reporting Items for Systematic Reviews and Meta-Analyses (PRISMA) statement (Fig. 1) [6]

\section{Results}

The literature search revealed 11 articles, 6 of which met the inclusion criteria and revealed 4 filter systems variations in used in surgical practice. The first article concerning risks of particle contamination in the smoke produced during laparoscopic surgery appeared in 1997 and interest arose on this subject continuously during the last decade [7].
For these studies, pneumoperitoneum was created and then electrocautery devices were used to generate smoke that was evacuated through filtering devices, which were analyzed.

\section{UGF1 Filter}

The first system for smoke collection and filtration was described in 1997 due to concern over metastasis in the port sites [7]. Nine laparoscopic procedures were evaluated using a chimney cannula attached to a UGF1 filter (Pall Biomedical, St. Germaine en Laye, France) through which fumes passed through a pore size of $0.5 \mu \mathrm{m}$. Further specification of the UGF1 filter was not available from the publication, authors, or after contacting the company. The filter analysis demonstrated mesothelial cells in six of nine samples, and electron microscopy revealed debris and identifiable cells in three. There were no metastases found in the port sites on follow-ups.

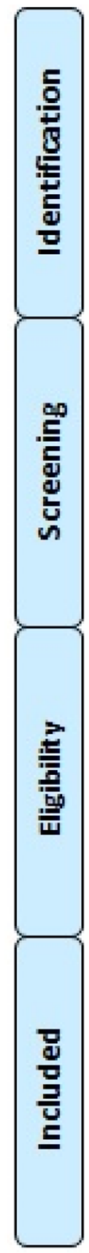

Records identified through database search ( $n=11)$ Records excluded $(n=2)$

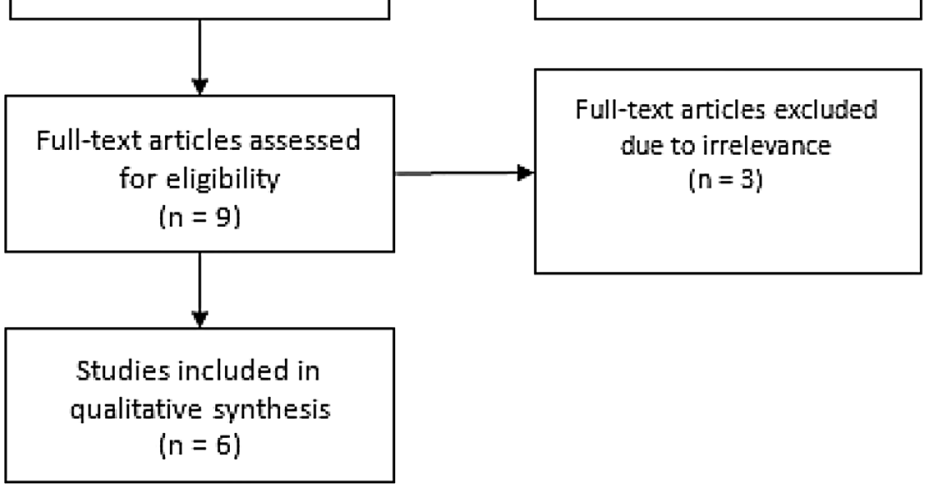

Fig. 1 PRISMA statement for systematic review of smoke filter investigations applied in endoscopic surgery 


\section{Ultra-low particulate air (ULPA) filter}

\section{2a. ULPA built-in port}

Focusing on maintaining pneumoperitoneum, a valve-less port AirSeal ${ }^{\mathrm{TM}}$ (SurgiQuest, Orange, CT) fitted with a $0.1 \mu \mathrm{m}$ ULPA filter was investigated [8]. This system maintained insufflation by creating a pressure barrier, while capturing the escaping gas that was filtered and then redirected into the port. This valve-less port was reported to have expeditious smoke evacuation and filtration, and demonstrated reduced exposure of staff to hazardous fumes.

\section{2b. UPLA with automatic smoke evacuator}

An automatic smoke evacuator in laparoscopic surgery was investigated using an industrial smoke-detection device [9]. Smoke was generated using a high-frequency electrosurgical unit (HF-ESU) and laparoscopic coagulating shears (LCS) and evacuated by the automatic smoke evacuator Erbe IES2 (Erbe Elektomedizin GmBH, Tübingen, Germany) equipped with a smoke absorptive membrane (\#7-510-16, Northgate Technologies Inc., Scottsdale Court, IL). The volume of residual smoke using an HF-ESU was found to be significantly lower in the evacuation group $(47.4 \pm 16.6)$ than the control group $(76.7 \pm 2.4, P=0.0018)$. Also, the amount of surgical smoke after LCS was significantly lower in the evaluation group $(21.3 \pm 10.7)$ versus control group $(75 \pm 39.9, P=0.044)$. The filtered contents investigated by gas chromatography and mass spectrum analysis identified 37 substances, three of which were carcinogenic according to the International Agency Research on Cancer (IRAC) and identified as acetaldehyde, dimethylformaldehyde, and furfural.

\section{3a./b. Charcoal filter}

Two groups reported the use of a Tropian trocar (Tropian Tech., Gunpo, Korea) that has a built-in filter made of two layers of processed and refined charcoal $[10,11]$. Each layer has $1200 \mathrm{~m}^{2} / \mathrm{g}$ surface to absorb a large amounts of smoke. The space between the two charcoal layers is occupied by innumerable $1-50 \mu \mathrm{m}$ micropores designed to trap liquid and aerosolized substances. These studies evaluated smoke generated by (1) laparoscopic nephrectomies using electrocautery and Harmonic Generator 300 (Ethicon Endo-Surgery Inc., Cincinnati, OH);[9] and by (2) laparoscopic or robot assisted procedures for benign uterine diseases using electrocautery, SurgiwandTM (Medtronic, Minneapolis, MN, USA) or HotShears ${ }^{\mathrm{TM}}$ EndoWrist cautery (Intuitive Surgical, Sunnyvale, CA, USA) [11]. The smoke filtered through the Tropian trocar was processed by ultra-performance liquid chromatography. Surgical smoke was analyzed for a number of hazardous substances to which exposure is regulated by the National Institute of Occupational Safety and by the Occupational Safety and Health Administration and yielded comparable rates of filtration for the traced substances (Table 1) [12].

\section{Charcoal and ULPA combined filter}

The Dyeing and Finishing Technology Institute filter device consists of a glass cylinder with a hole on top where the air enters and is then passed through a complex filter that had multiple layers of activated carbon fiber, ultra-low particulate air, and antiviral filters [13]. The post-filter smoke was then analyzed to determine the rate of volatile organic compounds that the filter can eliminate. The total elimination rate of the compounds was $86.49 \pm 2.83 \%$; of which four were carcinogenic and their elimination rates were 1,2-dichloroethane $84.5 \pm 6.0 \%$, benzene $92.6 \pm 2.9 \%$, ethylbenzene $93.1 \pm 8.4 \%$, and styrene $98.8 \pm 4.8 \%$, respectively.

A total of 62 substances were identified in techniques $2 \mathrm{~b}$, $3 \mathrm{a}, 3 \mathrm{~b}$, and 4 with approximately $20 \%$ of these substances confirmed in two or more techniques (Table 2) [9-11, 13].

\section{Discussion}

With increasing popularity of laparoscopy, many researchers commenced investigations on potentially harmful particles and substances generated by electric cauterization during these procedures. These by-products were identified to pose a risk not only to the patient, but also to the entire operating theater staff $[1,2]$. The present COVID-19 pandemic has again put these concerns into spotlight, leading many specialty organizations and hospitals to recommend restrictions or even completely exclude laparoscopic surgeries due to

Table 1 Comparison of removal rates of hazardous substances using the Tropian filter

\begin{tabular}{lll}
\hline Chemicals & \multicolumn{2}{l}{ Removal rate (\%) } \\
\cline { 2 - 3 } & Hahn et al. [9] & Ha et al. [10] \\
\hline Benzene & 69 & 38 \\
Toluene & 72 & 69.4 \\
Ethyl benzene & 46 & 77.8 \\
Xylene & 44 & 100 \\
Styrene & 35 & 66.7 \\
Formaldehyde & 39 & 50.6 \\
Acetaldehyde & - & 23.7 \\
Propionaldehyde & 33 & 0 \\
Butyraldehyde & 60 & 10.7 \\
Isovaleraldehyde & - & 20 \\
Veraldehyde & - & \\
\hline
\end{tabular}


Table 2 Substances identified in smoke generated by laparoscopic procedures

\begin{tabular}{|c|c|c|c|c|}
\hline & $\begin{array}{l}\text { Takahashi } \\
\text { et al. [9] }\end{array}$ & Choi et al. [13] & Hahn et al. [10] & Ha et al. [11] \\
\hline Acetaldehyde & $\mathrm{x}$ & & $\mathrm{x}$ & $\mathrm{x}$ \\
\hline Propanol & $\mathrm{x}$ & & & \\
\hline Acetone & $\mathrm{x}$ & $\mathrm{x}$ & & \\
\hline Methyl alcohol & $\mathrm{x}$ & & & \\
\hline 2-Methylbutanol & $\mathrm{x}$ & & & \\
\hline 3-Methylbutanol & $\mathrm{x}$ & & & \\
\hline 2,3-Butanedione & $\mathrm{x}$ & & & \\
\hline Pentanol & $\mathrm{x}$ & & & \\
\hline Hexanal & $\mathrm{x}$ & & & \\
\hline Isopropenyl methyl ketone & $\mathrm{x}$ & & & \\
\hline 1-Methoxy-2-propanol & $\mathrm{x}$ & & & \\
\hline n-Butanol & $\mathrm{x}$ & & & \\
\hline Heptanal & $\mathrm{x}$ & & & \\
\hline Dodecane & $\mathrm{x}$ & & & \\
\hline Ethylene glycol ethyl ether & $\mathrm{x}$ & & & \\
\hline 2-Pentylfuran & $\mathrm{x}$ & & & \\
\hline $\begin{array}{l}3,3,4,4,5,5,6,6,7,7,8,8 \text {-Tride- } \\
\text { cafluoro-1-octanol }\end{array}$ & $\mathrm{x}$ & & & \\
\hline Octanol & $\mathrm{x}$ & & & \\
\hline 1-Hepten-3-one & $\mathrm{x}$ & & & \\
\hline 1-Hydroxy-2-propanone & $\mathrm{x}$ & & & \\
\hline Dimethylformamide & $\mathrm{x}$ & & & \\
\hline Nonanal & $\mathrm{x}$ & & & \\
\hline Ethylene glycol butyl ether & $\mathrm{x}$ & & & \\
\hline N,N-Dimethylacetamide 3672 & $\mathrm{x}$ & & & \\
\hline 1,3-Ditertiarybutylbenzene & $\mathrm{x}$ & & & \\
\hline 1-Octen-3-ol & $\mathrm{x}$ & & & \\
\hline Acetic acid & $\mathrm{x}$ & & & \\
\hline Furfural & $\mathrm{x}$ & & & \\
\hline 2-Ethylhexanol & $\mathrm{x}$ & & & \\
\hline Decanal & $\mathrm{x}$ & & & \\
\hline Pyrrole & $\mathrm{x}$ & & & \\
\hline Benzaldehyde & $\mathrm{x}$ & & & \\
\hline Propanoic acid & $\mathrm{x}$ & & & \\
\hline Ethylene glycol isopropyl ether & $\mathrm{x}$ & & & \\
\hline Diethylene glycol ethyl ether 101 & $\mathrm{x}$ & & & \\
\hline 2-Furanmethanol & $\mathrm{x}$ & & & \\
\hline Xylene & & $\mathrm{x}$ & $\mathrm{x}$ & $\mathrm{x}$ \\
\hline Ethanol & & $\mathrm{x}$ & & \\
\hline 2-Butanone & & $\mathrm{x}$ & & \\
\hline Hexane & & $\mathrm{x}$ & & \\
\hline 1,2-Dichloroethane & & $\mathrm{x}$ & & \\
\hline Benzene & & $\mathrm{x}$ & $\mathrm{x}$ & $\mathrm{x}$ \\
\hline$N$-Heptane & & $\mathrm{x}$ & & \\
\hline Toluene & & $\mathrm{x}$ & $\mathrm{x}$ & $\mathrm{x}$ \\
\hline Ethylbenzene & & $\mathrm{x}$ & $\mathrm{x}$ & $\mathrm{x}$ \\
\hline p-Xylene & & $\mathrm{x}$ & & \\
\hline Styrene & & $\mathrm{x}$ & $\mathrm{x}$ & $\mathrm{x}$ \\
\hline N-nonane & & $\mathrm{x}$ & & \\
\hline o-Xylene & & $\mathrm{x}$ & & \\
\hline
\end{tabular}


Table 2 (continued)

\begin{tabular}{|c|c|c|c|c|}
\hline & $\begin{array}{l}\text { Takahashi } \\
\text { et al. [9] }\end{array}$ & Choi et al. [13] & Hahn et al. [10] & Ha et al. [11] \\
\hline$N$-Decane & & $\mathrm{x}$ & & \\
\hline $\mathrm{N}$-Undecane & & $\mathrm{x}$ & & \\
\hline$N$-Hexadecane & & $\mathrm{x}$ & & \\
\hline$N$-Tridecane & & $\mathrm{x}$ & & \\
\hline$N$-Tetradecane & & $\mathrm{x}$ & & \\
\hline$N$-Heptane & & $\mathrm{x}$ & & \\
\hline Butyraldehyde & & & $\mathrm{x}$ & $\mathrm{x}$ \\
\hline Formaldehyde & & & $\mathrm{x}$ & \\
\hline Propionaldehyde & & & $\mathrm{x}$ & $\mathrm{x}$ \\
\hline Isovaleraldehyde & & & $\mathrm{x}$ & $\mathrm{x}$ \\
\hline Valeraldehyde & & & $\mathrm{x}$ & $\mathrm{x}$ \\
\hline Formaldehyde & & & $\mathrm{x}$ & $\mathrm{x}$ \\
\hline Butyraldehyde & & & & $\mathrm{x}$ \\
\hline
\end{tabular}

possible virus transmission along with the evacuated pneumoperitoneum [14]. Smoke filters have suddenly gained the spotlight in this pandemic as potential devices for SARSCoV-2 virions filtration that could be expelled along with smoke during endoscopic surgical procedures.

Harmful smoke appears in both open and laparoscopic surgeries when cautery or other energy-powered devices are used. However, unlike open surgery, in laparoscopy, the smoke is initially concentrated in the abdomen under a lowoxygen atmosphere and then escapes under pressure during instrument changes or at the end of the procedure when the valves are opened to evacuate the pneumoperitoneum [10]. Smoke and gas can also exit around the port sites as the skin is not perfectly sealed around them. Hence, even though both approaches have the propensity to generate aerosols, the overall risk has been estimated to be lower with open surgery [15]. To address this issue, researchers focused on testing smoke filters in laparoscopy for gases escaping/evacuating during procedures with the intention of protecting medical personnel.

The first report regarding laparoscopic smoke-generated risks appeared following evidence of metastases arising in port sites [7]. Investigations on the UGF1 filtration system after use demonstrated clumps of whole cells, blood, and mesothelial cells attached to the filter. Though this report focused only on the aerosolized cells which could implant themselves in port sites along with the escaping air, it also underlined the implications of aerosolization for operating room theater staff. Though this study met the inclusion criteria in the present systematic review, specific information on the filtration system used in this device was not available. Also, since the product cannot be commercially purchased after over 20 years of the report being published, it may not be relevant to further investigate its characteristics in the context of the present pandemic.
The report on the ULPA built-in smoke filter used a system that enabled air filtration as part of a recirculation system designed to maintain pneumoperitoneum [8]. The mechanism used here created a pressure barrier acting as a valve by redirecting escaping gas through the filter and back to the abdomen. Using a valve-less port, there was a decrease in consumption of $\mathrm{CO}_{2}$, meaning that there was lesser gas escape through ports while changing instruments. The filter had the added benefit of clearing the smoke that also impeded vision. This technique of reducing gas evacuation in the operating room acted as further protection for the surgical team against potential hazards of the electrosurgical smoke.

Although no peer-reviewed reports were found on many of the present commercially available smoke evacuation devices, it is important to categorize these devices to better understand their filtration mechanisms. Karl Storz single-use smoke evacuation filters (Karl Storz, Tuettlingen, Germany), SeeClear® XCL ${ }^{\mathrm{TM}}$ (CooperSurgical Inc., Turnbull, CT), and PlumePort ${ }^{\circledR}$ (Conmed, Utica, NY) use ULPA filters for smoke management. The PlumePort ${ }^{\circledR}$ and SeeClear $₫$ $\mathrm{XCL}^{\mathrm{TM}}$ devices have activated carbon coupled with these devices, with the PlumePort ${ }^{\circledR}$ additionally offering a dualmanagement moisture control process of a wicking agent and fluid trap. PlumePort ${ }^{\circledR}$ ActiV® and PlumePort ${ }^{\circledR}$ SEO are active versions of PlumePort ${ }^{\circledR}$ that can be connected to suction systems. S-PILOT® (Karl Storz, Tuettlingen, Germany) also offers an automated system for smoke suction and filtration.

Four reports (Filter system $2 b, 3 a, 3 b$, and 4) focused their investigations specifically on substances identified in filtered smoke. Tissue decomposition by high-temperature ablation is known to produce breathable aerosols, complex organic chemicals, and cellular debris [16]. Therefore, in these techniques, the carbon compounds with carcinogenic 
risk were evaluated. These studies showed that using a filter can reduce the levels of certain compounds in the surgical plume. Takahashi et al. in 2013 also demonstrated that a great number of carbon-based substances are filtered in surgical smoke [9]. These substances are classified as toxic or harmful by the International Agency for Research on Cancer (IRAC) and workplace exposure to them is limited by the EH40/2005 workplace exposure limits [17]. This group reported that a significantly lower amount of room smoke is detected in the presence of smoke evacuators.

The Tropian trocar with a built-in charcoal/ULPA combination filter has been found to be a simple and effective way of reducing the exposure of surgical smoke filled with volatile organic compounds to surgeons and operating room personnel $[10,11]$. The different filtration rates with the use of these devices in the two reports as evident in Table 1 has been attributed to the difference in methodology and use of various additional devices.

In 2018, Choi et al. demonstrated that strong carcinogens were eliminated by more than $85 \%$ using an activated carbon filter, reducing the risks from these compounds to an almost negligible level. In these four techniques (Filter system $2 b$, $3 a, 3 b$, and 4), 62 substances were identified through filtration, but only a one-fifth of them appeared in two or more techniques as researchers focused their attentions on certain compounds and reported them using different nomenclature. All of these filter systems seem to be efficient in filtering out harmful particles either by clearing cells as in Filter system 1, or by preventing air leakage as in Filter system $2 a$ or by eliminating dangerous chemical substances as in Filter systems $2 b / 3 a / 3 b / 4$.

These selected studies have shown that endoscopic smoke evacuation filters have specifically focused on smoke analysis and filtration; however, the SARS-CoV-2 pandemic has led to their sudden interest for virus filtration. To date, none of the studies on smoke evacuation filters have investigated the filtration of virus as none of them were performed during a pandemic seen on the present scale. SARS-CoV-2 virions are approximately $0.125 \mu \mathrm{m}$ (range $0.06-0.14 \mu \mathrm{m}$ ) in size and are transmitted as larger $(>20 \mu \mathrm{m})$ respiratory water droplets or aerosolized smaller droplets $(<10 \mu \mathrm{m})[18,19]$. Presently available filters such as ULPA can screen particles of $0.1 \mu \mathrm{m}$ and high-efficiency particulate air filters (HEPA) particles of $0.3 \mu \mathrm{m}$ [20]. Data on size of smoke associated virons is not available.

Another complex issue in COVID-19 is the transmission mode of SARS-CoV-2. Viral RNA from COVID-19 patients has been detected by molecular studies in upper and lower respiratory tract samples, faeces and blood, indicating the potential presence of an infectious virus [14]. Though viral RNA may be detected in blood, no transmission of COVID19 has been documented through this route [21]. With specific note of caution to endoscopic surgery, the presence of
SARS-CoV-2 has also been confirmed in peritoneal fluid [22].

Viruses such as HIV, and hepatitis B and C have been detected in surgical smoke [18, 23] without documented risk of transmission from laparoscopic plume.

In conclusion, the efficacy of smoke filters have not been tested in peer-reviewed clinical studies on virus filtration, and controlled studies are needed to confirm whether the commercially available filters available for endoscopic surgery are also capable of effectively filtering SARS-CoV-2 virions.

\section{References}

1. Mattes D, Silajdzic E, Mayer M, Horn M, Scheidbach D, Wackernagel W, Langmann G, Wedrich A (2010) Surgical smoke management for minimally invasive (micro) endoscopy: an experimental study. Surg Endosc 24:2492-2501

2. Choi SH, Kwon TG, Chung SK, Kim TH (2014) Surgical smoke may be a biohazard to surgeons performing laparoscopic surgery. Surg Endosc 28:2374-2380

3. Alp E, Bijl D, Bleichrodt RP, Hansson B, Voss A (2006) Surgical smoke and infection control. J Hosp Infect 62:1-5

4. Kwak HD, Kim SH, Seo YS et al (2016) Detecting hepatitis B virus in surgical smoke emitted during laparoscopic surgery. Occup Environ Med 73:857-863

5. SAGES.org [Internet] SAGES and EAES Recommendations Regarding Surgical Response to COVID-19 Crisis - SAGES. Available from: https://www.sages.org/recommendations-surgi cal-response-covid-19/?fbclid=IwAR2M139pV3bwWp9XYB 2cfWy Ygrnx bks0W3GZ_sZ0GrGXVucZQULX qOf7Jfk. Accessed 16 May 2020

6. Moher D, Liberati A, Tetzlaff J et al (2009) Preferred reporting items for systematic reviews and meta-analyses: the PRISMA statement. PLoS Med 6:e1000097

7. Champault G, Taffinder N, Ziol M, Riskalla H, Catheline JM (1997) Cells are present in the smoke created during laparoscopic surgery. Br J Surg 84:993-995

8. Herati AS, Atalla MA, Rais-Bahrami S et al (2009) A new valveless trocar for urologic laparoscopy: initial evaluation. J Endourol 23:1535-1539

9. Takahashi H, Yamasaki M, Hirota M, Miyazaki Y, Moon JH, Souma Y, Mori M, Doki Y (2013) Nakajima K automatic smoke evacuation in laparoscopic surgery: a simplified method for objective evaluation. Surg Endosc 27:2980-2987

10. Hahn KY, Kang DW, Azman ZAM, Kim SY (2017) Kim SH removal of hazardous surgical smoke using a built-in-filter trocar: a study in laparoscopic rectal resection. Surg Laparosc Endosc Percutan Tech 27:341-345

11. Ha HI, Choi MC, Jung SG, Joo WD, Lee C, Song SH, Park H (2019) Chemicals in surgical smoke and the efficiency of builtin-filter ports. JSLS 23(e2019):00037

12. CDC.gov [Internet] National Institute for Occupational Safety and Health. Control of smoke from laser/electric surgical procedures. 1996. https://www.cdc.gov/niosh/docs/hazardcontrol/pdfs/hc11. pdf. Accessed 16 May 2020

13. Choi SH, Choi DH, Kang DH, Ha YS, Lee JN, Kim BS, Kim HT, Yoo ES, Kwon TG, Chung SK (2018) Kim TH Activated carbon fiber filters could reduce the risk of surgical smoke exposure 
during laparoscopic surgery: application of volatile organic compounds. Surg Endosc 32:4290-4298

14. Mallick R, Odejinmi F, Clark TJ (2020) Covid 19 pandemic and gynaecological laparoscopic surgery: knowns and unknowns facts views. Vis Obgyn. 12:3-7

15. Li CI, Pai YJ, Chen CH (2020) Characterization of smoke generated during the use of surgical knife in laparotomy surgeries. J Air Waste Manag Assoc 70:324-332

16. Barrett W, Garber S (2003) Surgical smoke: a review of the literature. Surg Endosc 17:979-987

17. Health and Safety Executive- EH40/2005 Workplace exposure limits. 4th ed. Norwich: The Sationery Office (Williams Lea); 2020. pp 9-22. Available online: https://www.hse.gov.uk/pubns/ priced/eh40.pdf

18. Morris SN, Fader AN, Milad MP, Dionisi HJ (2020) Understanding the "scope" of the problem: why laparoscopy is considered safe during the COVID-19 pandemic. J Minim Invasive Gynecol. https://doi.org/10.1016/j.jmig.2020.04.002

19. Zhu N, Zhang D, Wang W, Li X, Yang B, Song J, Zhao X, Huang B, Shi W, Lu R, Niu P, Zhan F, Ma X, Wang D, Xu W, Wu G, Gao GF, Tan W (2020) China novel coronavirus investigating and research team. N Engl J Med. 382:727-733
20. GTTLAB.com [Internet] CEN, Standard EN 1822- High efficiency air filters (EPA, HEPA and ULPA) European Committee for Standardization, Brussels, Belgium. https://www.gttla b.com/uploads/soft/161025/EN1822-1-2009Highefficiencyairfilt ers(EPA,HEPAandULPA)Part1Classification,performance.pdf. Accessed 16 May 2020

21. AABB.org [Internet] Advancing Transfusion and Cellular Therapies Worldwide Update- Impact of 2019 Novel Coronavirus and Blood Safety: https://www.aabb.org/advocacy/regulatorygover nment/Documents/Impact-of-2019-Novel-Coronavirus-on-Blood -Donation.pdf\#search=coronavirus\%20impact. Accessed 16 May 2020

22. Coccolini F, Tartaglia D, Puglisi A et al (2020) "SARS-CoV-2 Is Present in Peritoneal Fluid in COVID-19 Patients." Ann Surg. http://journals.lww.com/annalsofsurgery/Documents/SARSCoV-2\%20is\%20present\%20in\%20peritoneal\%20fluid\%20in\%20 COVID-19\%20patients.pdf

23. Baggish MS, Poiesz BJ, Joret D, Williamson P, Refai A (1991) Presence of human immunodeficiency virus DNA in laser smoke. Lasers Surg Med 11:197-203 